\title{
La prensa masónica en la Andalucía del siglo XIX: una aproximación a los orígenes gaditanos (*)
}

\author{
EDUARDO ENRIQUEZ DEL ARBOL \\ (Universidad de Granada)
}

\section{SUMARIO}

1. Introducción

2. Los orígenes de la prensa masónica gaditana

2.1. El Boletín Masónico de San Fernando (1881)

2.2. El Triángulo (1883-1884)

3. Conclusiones

\section{INTRODUCCION}

La apertura sin trabas del rico Archivo Histórico Nacional de Salamanca y la fundación del Centro de Estudios Históricos de la Masonería Española en 1984, fueron dos jalones fundamentales que han hecho posible la investigación científica de un tema, retenido tabú hasta tiempos bien recientes, como ha sido la Masonería. Se abrió así una corriente de investigación que desde ese momento ha ido cubriendo una serie de objetivos encaminados a esclarecer el conocimiento de un campo mal estudiado de nuestra historia contemporánea. Una historia fehaciente, a partir del Sexenio Revolucionario, apoyada en fuentes documentales, casi exclusivamente conservadas en el citado archivo salmantino (1).

(*) Este trabajo fue presentado en el I Congreso de Historia Contemporánea de Andalucía, celebrado en Málaga del 1 al 4 de mayo de 1990.

(1) Cuatro Symposiums celebrados en distintas capitales de España avalan la enjundia de los esfuerzos realizados hacia aquel cometido, desmitificando la idea que se tenía de una asociación considerada "tenebrosa" y causa de los males sociales, en otras palabras, destruir la pseudo-historia tópica formulada hasta entonces. Y lo 
Es bien sabido que en esa historia que se está elaborando de la Masonería hispana, Andalucía jugó un papel muy importante desde sus inicios, no sólo por su aparición temprana y su adscripción a movimientos liberales del primer tercio del siglo XIX, cuya incidencia todavía reviste interpretaciones diversas. Baste recordar, tras la Revolución Septembrina (2), el gran número de sus afiliados y la categoría social y política de gran parte de ellos. No podía faltar en este estudio interno en profundidad, la prensa masónica.

Este trabajo, dada su preceptiva brevedad, tiene el propósito de presentar una investigación, desde dentro de la Institución, sobre la producción impresa de los masones andaluces, en un caso concreto: el que se refiere a los orígenes de la prensa gaditana.

\section{LOS ORIGENES DE LA PRENSA MASONICA GADITANA}

A pesar de la importancia que tuvo la Masonería en la provincia de Cádiz durante el período del Sexenio, con respecto a las demás provincias andaluzas (3), sorprendentemente no aparece ninguna publicación de ese carácter. Será en la primera etapa de la Restauración, que coincide con la más brillante de la Institución en Cádiz (4), cuando surgen los primeros periódicos masónicos: el Boletín Masónico de San Fernando y El Triángulo de Cádiz. De ellos trataremos en las líneas que siguen.

que era ayer un pequeño grupo de estudiosos, hoy se aproximan a un centenar los especialistas que han dedicado parte de su investigación a la historia de la Orden del Gran Arquitecto del Universo.

(2) Sobre la conexión de la Masonería con la política y con la sociedad, se han emprendido una serie de estudios, una vez superado el estadio de la investigación interna de la Masonería, y así en las Actas publicadas de los Symposiums celebrados aparecen los apartados correspondientes dedicados a: "Los Masones y su influjo social", "Aspectos ideológico-políticos de la Masonería", "Masonería y republicanismo", etc.

(3) Las logias masónicas gaditanas suponen un tercio del conjunto regional. Cfr. ENRIQUEZ DEL ARBOL, E.: "La nueva sociabilidad clandestina: Hacia la historia de la Masonería gaditana desde las Cortes de Cádiz a la Restauración", en III Encuentros de la Ilustración al Romanticismo. Cádiz, Europa y América ante la Modernidad (1750-1850). Universidad de Cádiz, 1987 (en prensa).

(4) Véase mi estudio, "Las logias gaditanas en el primer periodo de la Restauración (1874-1885)", en Actas del I Coloquio de Historias Locales, Cádiz, fundación Rafael Alberti, 1989, (en prensa). Se fundaron de nueva planta 34 logias, que duplican las del Sexenio. 


\subsection{El Boletín Masónico de San Fernando (1881)}

\subsubsection{Orígenes}

Es la primera publicación que aparece en Cádiz, en octubre de 1881, y concretamente en San Fernando, que contaba con una larga tradición masónica al tener logia propia desde 1870, acrecentando su número en años posteriores. De la publicación sólo nos ha llegado un ejemplar, y nada sabríamos de su existencia a través de otras fuentes masónicas, si no fuese por $E l$ Taller, órgano oficial de la Confederación Masónica del Congreso de Sevilla y de la Gran Logia Simbólica Independiente Española (5).

¿Quienes fueron sus fundadores? Difícil respuesta, puesto que los entes masónicos funcionantes en ese momento en San Fernando no aparecen aparentemente vinculados a la publicación (6) y sí a un taller, la Unión y Fuerza, del que no sabemos hasta el momento otra cosa que esta noticia. Ignoramos a qué obediencia pertenecía, porque no figura en ninguno de los listados que se tienen de los Orientes (7). En agosto de 1890, transcurridos nueve años, una documentación gaditana nos habla de una Unión y Fuerza, que iba a fundarse bajo el Gran Oriente Nacional de España del Vizconde de Ros, antes de convertirse en el Gran Oriente Ibérico, y que podemos colegir derivada

(5) Así, acusando recibo a las publicaciones masónicas cuya visita habían recibido por primera vez, cita al Boletín Masónico de San Fernando (E.T., Año II, n. 46, 30-XI1881, Muy bienvenidos, p.3).

(6) Si dejamos de lado las logias Estrella de León y Cosmopolita, que seguían la obediencia tachada de "irregular" del paradójicamente llamado Gran Oriente Regular de Antonio Pérez, y que al parecer habían consumido su ciclo vital, existían las siguientes: La $L u z$ n. 12, perteneciente a la Gran Logia Simbólica Independiente Española; la Estrella Meridional n. 113 y Observatorio n. 116, bajo el Grande Oriente nacional; y las tres siguientes del Gran Oriente de España: Hijos de la Verdad n. 30, Hijos de la Ciencia n. 64 e Hijos del Progreso n. 85.

(7) Cabe pensar que fuese fundada bajo el Gran Oriente de España, ya que en la enumeración de las logias de este alto organismo que publicó Ferrer Benimeli, hay lagunas que permiten sospechar que esta logia fuese una de ellas (FERRER BENIMELI, J.A.: "Implantación de logias y distribución geográfico-histórica de la Masonería española", en La.Masonería en la España del siglo XIX, Actas del II Symposium de Metodología aplicada a la historia de la Masonería española, Valladolid, Junta de Castilla y León, 1987, pp. 90-103). Apunta el citado profesor que es posible que no pocas de las logias que desaparecieron en el listado de diciembre de 1881, que figuraban en el anterior, correspondiesen a la escisión que el GODE "tuvo en 1876, protagonizado por Juan de la Somera', quien crearía su propia obediencia y que desaparecería con su muerte precisamente en 1881” (Ibídem., p. 95). 
de aquella primera Unión y Fuerza, ya que al parecer se aprovechó el sello, tachando su número de origen primitivo.

¿Formaron las logias de San Fernando un frente común para fundar este Boletin? Así lo parece indicar, como veremos seguidamente, el contenido de uno de sus artículos. En cuanto a los masones que en él aparecen, tampoco hemos podido averiguar mucho. De la logias sanfernandinas poseemos documentación únicamente de la Luz n. 12 de esa época, gracias al material que se conserva de la Gran Logia Simbólica Independiente establecida en Sevilla. ¿Pudo ser Sixto Cámara, uno de los que firman el Boletín Masónico, el profesor Angel Escandón Tuero, de 21 años de edad, natural de Santander y fundador de aquella logia en 1881? Otro simbólico que leemos en el Boletín, es Watt, que coincide con otro del mismo simbolismo de la referida logia (8).

\subsubsection{Ficha bemerográfica}

I. Ficha descriptiva (o registro de identificación)

Título: Boletín Masónico de San Fernando.

Subtítulo: Periódico de intereses generales de la Orden y locales de estos Valles.

Fecha de publicación: único número: n. 2, 15-XI-1881.

Lugar de edición: San Fernando.

Dirección de administración y redacción: Desconocida.

Frecuencia: Desconocida. Quizá quincenal (9).

Zona de difusión: Fundamentalmente provincia de Cádiz, con suscripciones en Córdoba, Huelva, Canarias y Puerto Rico.

Tirada: Sin precisar.

Precio: Se desconoce.

Formato: $30 \times 21 \mathrm{cms}$.

Espacio impreso: $24 \times 16 \mathrm{cms}$.

Número de páginas: 8 más portada.

Columnas por página: Dos.

Centímetros por columna: $7,8 \mathrm{cms}$.

Imprenta: No se sabe.

Localización: A. H. N. Sección Guerra Civil (Masonería), Legajo M-179.

Objeto: Defensa de los intereses de la Masonería.

(8) Se trata de Federico Lacosta, maquinista de 23 años de edad, que debió haber sido iniciado en la $L u z$ por aquellas fechas.

(9) Se nos dice en el ejemplar conservado que se publicaría otro número el 30 del mismo mes. 
II. Estructura básica (o expediente de identidad)

Sobre esta no hemos podido saber nada hasta el momento, al carecer de datos.

Estructura jurídica: Propiedad particular (logias fundadoras)

Dependencia: Suscripción.

III. Características tipográficas o Morfología

Superficie impresa total: $3.072 \mathrm{cms} .2$.

Número de páginas: 8 :

Superficie redaccional: Titulares: $169,30 \mathrm{cms}$.

Textos: $2.902,70 \mathrm{cms}$.

Enumeración de secciones: Editorial (10).

Intereses generales

Sección local

Sección de noticias

Advertencia

Correspondencia del Boletin

Unidades redaccionales: Informaciones, 1

Artículos, 5

Extracto de prensa, 1

Secciones de servicios, 1.

\subsubsection{Análisis de contenido}

El Boletín, en su subtítulo, nos indica claramente el objetivo concebido por sus fundadores: defender a la orden masónica y no a los grupúsculos españoles que la componían (11). Es decir, superar a los distintos intereses de las Obediencias diversas a las que pertenecían los talleres de San Fernando.

(10) Quizá no debiera llamarse así, ya que aparece como un artículo más, bajo el epígrafe, en este caso, de "Protesta".

(11) Aquí lo que se estaba ventilando, en realidad, era el simbolismo, que apareció por vez primera como una reivindicación efectiva precisamente en Andalucía, dos años antes, en el momento de la ruptura de algunas logias andaluzas con el Gran Oriente Lusitano Unido y la formación de la Gran Logia Simbólica Independiente Española en Sevilla. En la publicación no aparece ningún masón con grado superior al de maestro, lo que nos indica su adhesión a la Masonería primigenia de los tres primeros grados. Postura que refuerza; como veremos, $E l$ Triängulo. 
En este único ejemplar que poseemos del Boletín, se trata de esta cuestión de carácter general que en España se presentaba rozando la "irregularidad", incidiendo sobre la creencia y la moralidad masónicas: la desunión. Tres artículos del periódico van dirigidos al remedio de esa grave falta: "El jurado masónico", la "Unidad Masónica" y "A nuestros hermanos".

En el primero se hacía una defensa cerrada de la voz de la razón y del amor fraternal, solución a los males que aquejaban a la Institución (carencia de sentimientos de fraternidad y de fe masónica), compuesta a veces por hermanos que se dejaban arrastrar por móviles personales (12). Para cortar abusos, la constitución de un jurado de honor, o jurado masónico, que podía oponerse a los antimasónicos actos de los falsos o extraviados hermanos, llenando su cometido tan pronto como ocurriera el primer síntoma de agresión u ofensa, volando hacia el hermano ofendido, recordarle cuáles fueron sus juramentos y arrancándole la promesa formal de no buscar personalmente la vindicación o satisfacción necesaria, que encomendaría a los hermanos que formasen aquél". Era, pues, una misión de paz que velaría por el prestigio necesario a la Masonería (13).

En el segundo artículo, bajo el marbete de "A nuestros hermanos", firmado por Lincoln, gr. 3., se llamaba la atención sobre uno de los ideales que perseguía la Institución y que se presentaba más necesario que nunca: la sincera unión entre los masones, sin la que no se podía alcanzar "la meta colocada al final de nuestra larga y difícil peregrinación por el camino de la civilización y del progreso moral de la humanidad" (14).

(12) "Y siendo en consecuencia imprescindible, aunque triste reconocer que los afil. a la Aug. Inst. Mas. que tales actos provocan, penetraron en ella guiados de los móviles personales que constituyen las ambiciones o las debilidades humanas y que ni el amor a los bellos principios que la constituyen, ni a sus semejantes fueron su estrella polar, forzoso nos será el prenteder contrarrestar los actos de descrédito que provocan (...)" (B.M.S.F., Año I, n. 2, 15-XI-1881, "Sección de intereses generales. El jurado masónico", p. 2).

(13) "Detenido así el conflicto en sus primeros destellos ¿Cuál sería la misión del JURADO para con el h. ofensor? Es tan evidente y lógica que creemos inútil ocuparnos de ella (...)" (Ibídem).

(14) "No vea en nosotros el mundo profano el más pequeño indicio de disensión, ni de rencilla; que éstos son males ocasionados casi siempre por la vanidad, el orgullo y la intolerancia; vicios todos que por más que por sean inherentes a la personalidad humana, es preciso combatir con todas nuestras fuerzas, por la triste idea que dan del que en su pecho los abriga (...) Quédense en buen hora para el mundo profano esas vanidades y jerarquías ique nosotros tenemos títulos más preciados de vanagloria, que esos goces efímeros que solo afectan al exterior, halagando los sentidos y dejando vacío el corazón! (...)" (Ibídem., p. 6). 
Era una leit motiv que se repetirá constantemente en las preocupaciones de la Masonería española. Se exhortaba a todos los masones a la unión, ya que la Institución acercaba el hombre al hombre, por más enemigos que hubiesen sido. Había que desterrar la discordia, el antagonismo y la soberbia, y no olvidando que cada uno era el último entre todós sus iguales (15). Se exaltaba el ideal masónico de conseguir una agrupación de hombres libres y honrados desprovistos de sus mundanales preocupaciones y sin otra aspiración que un fin altamente moral y humanitario (16).

En el tercer artículo, la "Unidad Masónica", se defendía una unidad más concreta: la de los masones de San Fernando, como medio de preparar poco a poco la unidad general. Se daba como probable y se ponía en evidencia que las buenas intenciones podían ir al traste si se obligaba a acatar una determinada obediencia. Propugnaba en síntesis:

1) Reunión de todos los masones que representaban autoridad dentro y fuera de los talleres de la población, y con el compromiso bajo la palabra de honor, antes de poner a discusión tema ni derecho alguno, a prestar obediencia a aquel Supremo Consejo Español que se encontrase intima y legalmente constituido.

2) Debían llevar esta decisión a sus logias respectivas sin prejuzgar solución alguna, nombrándose comisiones de todas que examinasen los derechos que alegasen los Supremos Consejos españoles de ser cada cual el único y legalmente constituido.

3) Si hubiese "Autoridad masónica", que tal probara, a los masones de San Fernando, el juramento estaba hecho. La palabra, llevaría a todos al lado de aquel Supremo Consejo o de aquella Suprema autoridad.

4) En el caso de que ninguna de las logias pudiera presentar pruebas del verdadero reconocimiento universal del Supremo Consejo de su Obediencia, no se habrían perdido los esfuerzos, se seguiría trabajando acatando sus respectivas Obediencias, y esperarían tranquilos a que se les dijese: "Masones españoles, los Supremos Consejos de las potencias masónicas reunidos en Convento General, reconocen como único legítimo y legalmente constituido al Supremo Consejo que presi-

(15) "Purifiquemos nuestras filas de elementos heterogéneos y separemos cada nueva acometida de esa poderosa falange, aprestados y confundidos con una sola voluntad y un pensamiento único y vean por fin los eternos detractores en esta Sub. Ord. la luz radiante que nos inunda y que no podrán jamás distinguir como destello que es de la G. D. G. SA. D. U. " (Ibídem.).

(16) B. M. S. F., Año I, n. 2, 15-XI-1881, "Unidad masónica", pp. 6 y 7. 
de el H. M.". Estando los masones de San Fernando unidos, podría ser fácil el ser todos unos en Obediencia (17).

Las otras claves del contenido del Boletinn, son: La Masonería ante la Constitución y el Código Penal, copiado de El Taller, y que vio la luz en los valles de La Habana, con motivo de haber sido denunciado el periódico titulado Eco de Güines, que insertó un artículo en que se hacía la defensa y la apología de la Institución masónica y de cuya denuncia fue absuelto libremente (18); la creación de una asociación filantrópica de señoras que tenía por objeto distribuir las cantidades que las logias pusiesen a su disposición y las que recolectasen las asociadas. La Comisión de obreros de la Unión y Fuerza propondría la manera más conveniente de llevarlo a efecto, y no se dudaba del apoyo y protección de todos los hermanos de San Fernando. Lo interesante es que antes de que las logias de Buenos Aires creasen esta Sociedad Filantrópica de Señoras, cuya existencia se sabía a través de Le Monde Maçonnique de París, lo había pensado la logia sanfernandina (19).

Finalmente, debemos destacar un aspecto de gran interés social: la defensa de la escuela gratuita de adultos que la organización masónica mantenía abierta en San Fernando. La defensa de la Comisión Central de las logias fundadoras aparecía bajo la rúbrica de "Protesta" en la primera página. En ella se rechazaban las declaraciones del hermano Espartero, que había sostenido ante su logia, que la casi totalidad de los alumnos que acudían a la Escuela lo eran de pago, y que no comprendía el aumento de real por cotización ni la suscripción al periódico como medio de allegar recursos con que sostener una escuela que por sí misma se sostenía. Lamentaban el proceder del h. Espartero, al cual constaba que durante el primer trimestre, tan sólo dos alumnos de pago concurrieron a las clases. Y éstos fueron Francisco Cardoso y José Martín, hijo suyo (20). Por tanto, todos los ingresos que recibió en concepto de pago de alumnos fueron los honorarios de los jovenes citados:

"Y entendemos que si bien hasta cierto límite, son libres nuestros hermanos de acudir o no, con su óbolo al sostén de una Escuela, que en bien de la Aug. Inst. Mas. ha sido formada, son por el contrario

(17) Ibídem.

(18) B. M. S. F. , n. 2, 15-XI-1881, "Sección de noticias", p.7.

(19) "La Resp. Log. de este Or. Union y Fuerza, se había inspirado en los beneficios que este laudable y masónico proyecto podía proporcionar a la Ord., mucho antes de tener conocimiento alguno de que se tratase de realizarlos por las RR.LL. de Buenos Aires (...)" (Ibídem., p. 8).

(20) B. M. S. F., Año I, n. 2, 15-XI-1881, "Protesta", p. 1. 
reos de lesa Mason., al emitir frases que, faltas de toda verdad, puedan causar perjuicios a nuestra Ord., sino morales a determinados H.H.; y que, por los perjuicios que su ligereza pudiera ocasionar se hacen con ellos acreedores a ver sometido su proceder al fallo y censura de todos los Mas.

Esperamos, pues, que nuestros Il. y. Pod. H. Espartero, que con tanta fe se arrojó en brazos de nuestros salvadores principios de regeneración y verdad, que tiene dada en varias ocasiones pruebas de afecto hacia algunos de los $\mathrm{HH}$. que suscriben, que sabe que al retirar de la Escuela a su joven hijo, sólo quedó a la misma un alumno de pago; que sabe, por último, que las necesidades de la Escuela por su gasto de material y alumbrado, pesan sobre la garantía personal de la Com. central, rectificará sus palabras en lugar y acto tanto solemnes cual fueron vertidas, y en tal caso, con satisfacción suma y para bien de su nombre, nos apresuramos a consignarlo en el BOLETIN MASONICO, en lugar tan preferente cual lo hacemos hoy con nuestra Protesta a la que nos impulsa más bien un sentimiento de pena que no de enojo" (21).

Pocas cosas podemos decir más de este Boletín de San Fernando, que sospechamos nació con grandes dificultades en agosto de 1881, cuyo segundo número que comentamos vio la luz en Noviembre, y el tercero lo sería al parecer a fines del mismo mes. A partir de aquí no volvería a salir (22).

\subsection{El Triángulo de Cádiz (1883-1884)}

Dos años pasaron hasta la aparición de este segundo órgano de la prensa masónica gaditana, pero esta vez en la capital. Exactamente no sabemos cuando se funda, aunque debió ser a fines del otoño de 1883, a juzgar por el artículo con que El Taller saludaba su aparición como revista quincenal y órgano de la Masonería gaditana, recomendándola y elogiando su independencia y sus miras:

"El Triángulo no es un órgano de una agrupación determinada, ni tiene la misión de defender los derechos de ninguna de las Obediencias que existen en España. Ha venido al estadio de la prensa masónica para defender los grandes intereses de la Masonería y hacer propa-

(21) Ibídem.

(22) Esta es la impresión que se tiene al leer lo que escribe El Taller a la altura de febrero de 1882: que faltaba entre otras publicaciones, desde el n. 3, el Boletîn Masónico de San Fernando (E. T., Año III., n. 51, 15-II-1882, p. 8). 
ganda de sus trascendentales principios, abogando por la unión de la Gran Familia, cuyas disidencias tanto contribuyen a su desprestigio. Y el querido colega cumple perfectamente su misión. Sus artículos muy bien escritos por cierto, están nutridos de sana doctrina masónica y no dudamos recomendar su lectura a nuestros queridos hermanos en la seguridad que aprenderás mucho bueno. Reciba, pues, nuestro ilustre colega gaditano, nuestros más sinceros plácemes y prosiga con ardor en su tarea que es noble y merecerá las simpatías de todos" (23).

Nacía El Triángulo bajo el mismo clima que lo había hecho el anterior y con sus mismos propósitos: defender los grandes intereses de la Masonería y propagar sus principios. No hay duda que contó con el apoyo de la Gran Logia sevillana, y es posible que estuviese directamente vinculado a ella. En el artículo anteriormente citado de $E l$ Taller, subrayaba el organismo bético que se estaban haciendo grandes esfuerzos en Cádiz para regenerar la Masonería simbólica, emancipándola de la tutela de los altos poderes del escocismo. Las logias de la obediencia sevillana en la capital gaditana, Tolerancia y Fraternidad n. 1, Verdad n. 8, y Firmeza n. 22 que acababan de instalarse, habían solicitado la correspondiente carta para convertirse en Logia Provincial, y con el título de Gades Augusta, sería la primera que se formaría con arreglo a la nueva Constitución y Estatutos generales de la Gran Logia Simbólica Independiente, y serviría para dar impulso a la obra regeneradora entre los "muchos masones de Cádiz" (24).

Es muy poco más lo que podemos añadir sobre este periódico gaditano, al no poseer, desgraciadamente, fuentes documentales propias. En tres ocasiones aparece aún citado en $E l$ Taller. Así, en la presentación de su programa para 1884, la Gran Logia Simbólica de Sevilla, tras proclamar los intereses generales de la Masonería (25) y los

(23) E. T., Año IV, n. 95, 15-XII-1883, "La Masonería gaditana", p. 182. La correspondencia había de dirigirse a A. de N. Barragán, San Rafael, 8-2. Cádiz.

(24) Ibídem.

(25) Eran estos: Hacerla aparecer ante los poderes públicos como una Institución eminentemente social, de la que nada pudiera temer el orden público ni el progreso y bienestar de la patria; para conseguir que se la considerara como una asociación lícita garantizada por las leyes. Presentarla a los ojos de los extraños como una sociedad de hombres honrados que amaban el bien y odiaban el mal, y que por la instrucción y beneficencia se consagraban al bienestar de sus semejantes, sin otra recompensa que la satisfacción que traía siempre la práctica del bien. Defenderla de los injustos ataques de los fanáticos dirigidos por los jesuitas, los enemigos eternos de la sociedad, por lo mismo que aborrecían la luz, la libertad, el progreso de la civilización de los pueblos. -Trabajar con ahínco por la unión 
intereses especiales de la Institución (26), intenta ampliar el marco de la acción masónica, tomando parte más activa en aspectos sociales a los que creían debían prestar también atención. Había muchas otras cosas -dirían- de las que debían ocuparse para desarrollar los fines de la Orden" (27), reconociendo que no debían limitarse a los trabajos de educación y beneficencia, sino que debían ser una fuerza viva en el país, para "promover sus intereses en el comercio, la industria y la agricultura, las ciencias y las artes" (28). Esta afirmación reviste una especial importancia, porque sin desviarse ni desvirtuar los postulados masónicos, se hablaba de perseguir de un modo más dinámico aquellos objetivos de progreso que indicaban una importante preocupación social. El Taller, sin rodeos, veía la necesidad de ocuparse de cuestiones que eran de interés para la nación, entre las que enumeraba alguna de ellas (29). Y con este fin, rogaba a los hermanos de las provincias que indicasen cuáles eran las cuestiones que más directamente les

de todos los masones a fin de que desaparecieran los odios que alejaban unos de los otros, las intransigencias de partido que obigaban a mirarse como enemigos (Ibídem.).

(26) "Fomentar en las logias el espíritu masónico, avivando la fe de los tibios y atrayendo a las filas hombres formales y serios, arrojando de ellas a los que no servian más que para llevar la perturbación y el desaliento. -Extender por la propaganda de ideas y propósitos, el círculo de la Gran Logia, creando cuadros simbólicos donde se pudiera contar con hermanos. -Desarrollar más y más relaciones en el exterior hasta conseguir establecerlas con todas las potencias simbólicas del mundo. - Demostrar con las palabras y el ejemplo que a pesar de defender los derechos jurisdiccionales de la Gran Logia, estaban dispuestos a vivir en paz y buena armonía con los masones de otros Ritos, sosteniendo nuestros programas: Una Gran Logia para los tres grados del Rito Simbólico, un supremo Consejo para los altos grados de la Masonería dogmática" (Ibídem.).

(27) Creación de escuelas diarias para niños y niñas. Escuelas nocturnas para adultos. Escuelas de artes y oficios para obreros. Conferencias públicas. -Construcción de casas económicas para la clase obrera. -Constitución de una sociedad de socorros mutuos. -Cajas de Beneficencia (Ibídem.).

(28) "Los masones debemos salir del estrecho círculo de nuestras logias y lanzarnos a la vida pública, para iniciar o secundar en la prensa y en los circulos que frecuentamos, las grandes cuestiones económicas y sociales, que son de interés vital para las provincias y para la nación en general (...)" (Ibídem.).

(29) Cultivo de tabaco en todas las regiones que fuesen a propósito para ello. -Declaración de puerto franco a favor de Cádiz, para depósito de mercancías procedentes de América y Filipinas. -Fomento de relaciones comerciales con las antiguas posesiones españolas del Centro y Sud América. -Desarrollo del comercio con Africa creándose factorías y colonias en el Sur de la misma, como medio, entre otras cosas de evitar la emigración a América y extender nuestra legítima influencia en el territorio africano (...) (Ibídem.). 
interesaban, y en este caso nombraba especialmente a la revista gaditana:

"A su vez rogamos a nuestro querido colega El Triángulo de Cádiz, y a los demás periódicos masónicos que se publican en España y en Cuba, nos ayuden en esta empresa, de la que indudablemente reportará gran utilidad a nuestra patria común y mucho prestigio a nuestra institución" (30).

Hubiera sido interesante conocer si estos propósitos tuvieron resultados satisfactorios.

En el mes de marzo de 1884, El Triángulo daba reseña de la solemne ceremonia de la instalación de la Logia Provincial de Cádiz, verificada el 20 de febrero y que debió tener amplia resonancia en la ciudad (31). A poco, una nueva noticia sobre la revista gaditana aparecería en el periódico sevillano, con motivo de la publicación de una poesía (32).

Un mes más tarde, El Triángulo intervendría en el Concurso de Bases para un certamen masónico que habían promovido las logias gaditanas de la obediencia sevillana para premiar la mejor memoria. La redacción de la revista gaditana señalaba el tema: "Medios prácticos para lograr la unificación de la Masonería española", y creaba con tal motivo cuatro premios (33). Es la última noticia que hemos encontrado referente a esta revista de Cádiz.

\section{CONCLUSIONES}

I. Cádiz, a pesar de ser una provincia pionera en tantos aspectos ideológico-sociales y también en la Masonería, no contará sino tardía-

(30) Ibídem.

(31) E. T., Año V, n. 102, 30-III-1884, suelto, p. 238.

(32) Se le advertiría por la revista sevillana que la poesía publicada el 15 de marzo con el epígrafe "Adelante" como tomada de $L a$ Adelph, de Puerto Rico, fue originalmente publicada en $E l$ Taller, el 30 de marzo del año anterior, al reseñar el acto de la instalación de la logia Estrella Flamígera de Córdoba, en que fue leída por su autor, el hermano Ricardo Solier. De El Taller la habían tomado otros periódicos masónicos, a lo que no se oponían, si bien deseaban que se hiciera constar la legítima procedencia ( $E$. T., Año V, n. 163, 15-IV-1884, suelto, p. 248).

(33) Eran éstos: 1) Un objeto de arte; 2) Suscripción gratuita a El Triängulo, mientras durara la publicación; 3) Diploma artístico hecho a pluma y en colores, que conmemorara el triunfo del autor de la memoria, único en su ejecución y regalo de su autor el muy querido hermano Lincoln, grado 9; y 4) Veinticinco ejemplares impresos de la Memoria premiada (E. T., Año V, n. 104, 30-IV-1884, "Bases para un Certamen masónico", pp. 255). 
mente con una publicación claramente masónica. Bien es verdad que en esa etapa de la Restauración coincide con el periodo más brillante de la Institución en Cádiz.

II. Los orígenes de la prensa masónica gaditana se sitúan en la década de los ochenta: El Boletín Masónico de San Fernando, seguido de El Triángulo de Cádiz. Desconocemos del primero las logias masónicas que lo formaron, y del segundo suponemos que debían ser de las pertenecientes a la Obediencia sevillana (Gran Logia Simbólica Independiente Española).

III. Los contenidos de esta primera prensa gaditana giran en torno a dos temas centrales: la unión de la Masonería y la defensa de los intereses de la misma frente a terceros. Conectado a ellos, la defensa del simbolismo, que tuvo en Andalucía sus primeros brotes en 1879.

IV. Detectamos preocupaciones sociales en ambas publicaciones, lo que no es un fenómeno extraño a la Masonería en el periodo estudiado (34), al mismo tiempo que nos informan acerca de la actuación práctica, al menos en el campo de la enseñanza, que llevó a cabo la Masonería sanfernandina.

(34) Precisamente sobre estas preocupaciones, en la que ocupaba un lugar preferente la llamada "cuestión social", tenemos en elaboración un trabajo de investigación. 